\title{
Gender Equity in Leadership and Conferences of the Stroke Society of Australasia
}

\author{
Cheryl Carcel ${ }^{a, b}, c$ Mark Woodward $^{\mathrm{a}, \mathrm{d}, \mathrm{e}}$ Craig S. Anderson ${ }^{\mathrm{a}, \mathrm{b}, \mathrm{c}}$ \\ Candice Delcourt ${ }^{a, b, c}$ Julie Bernhardt ${ }^{f}$ Seana Gallg
}

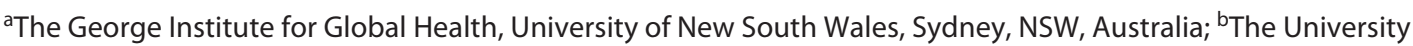
of Sydney, Sydney School of Public Health, Sydney Medical School, Sydney, NSW, Australia; 'Department of Neurology, Royal Prince Alfred Hospital, Sydney, NSW, Australia; ${ }^{\mathrm{d}}$ The George Institute for Global Health, Imperial

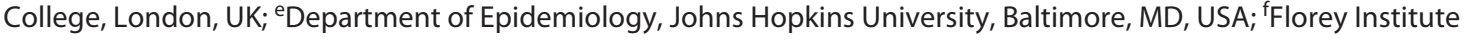
of Neuroscience and Mental Health, Austin Campus, Heidelberg, VIC, Australia; ${ }^{9}$ Menzies Institute for Medical Research, University of Tasmania, Hobart, TAS, Australia

\section{Keywords}

Gender · Stroke · Equity · Leadership

\begin{abstract}
Introduction and Aim: Internationally, women are underrepresented as leaders in major scientific organizations and conferences. We aimed to determine gender differences in leadership roles and annual scientific conferences of the Stroke Society of Australasia (SSA). Methods: In a retrospective review of SSA data (2014-2019), committee members were obtained through the SSA Web site, and moderators, speakers, and award recipients were identified from SSA annual scientific conference programs. Gender was determined by name inspection and Web search. Absolute numbers and proportions of women and men were recorded for all roles examined, overall and per year. Associations between representation of women in conferences and percentage of women in speaking roles were tested using multinomial regression. Results: Presidential leadership of the SSA was held by men in 2014-2016 and 2019 and women in 2017-2018. SSA committee membership was predominantly women (55\%), being lowest (47\%) in 2014 and 2019 and highest (65\%) in 2017. There was a wide gender variation at
\end{abstract}

scientific conferences, with $41 \%$ of keynote speakers being women overall, from 20\% in 2016 to $75 \%$ in 2015 . From 2014 to $2019,55 \%$ of all speakers were women, ranging from $32 \%$ (in 2016) to 71\% (in 2015). A higher percentage of women as speakers or moderators was associated with a program committee with over a third of its members composed of women ( $p \leq 0.044)$. Conclusions: Representation of women varied from 2014 to 2019 in the SSA organization and its conferences, although men are more often elected president in the organization and women are less often keynote speakers. When more women were included in the program committee, the representation of women as speakers increased.

C) 2021 S. Karger AG, Basel

\section{Introduction}

Recognition and reporting of gender disparities in medicine and academia has gained renewed interest in 2020 as the COVID-19 pandemic has highlighted differences in research outputs between women and men [1,2] that have been recognized previously $[3,4]$. Gender-related disparities in medical research have been reported in such areas as publishing, compensation, academic pro- 
Table 1. SSA leadership group from 2014 to 2019 by gender

\begin{tabular}{|c|c|c|c|c|c|c|c|c|c|c|c|c|}
\hline \multirow[t]{2}{*}{ SSA leadership group } & \multicolumn{2}{|l|}{2014} & \multicolumn{2}{|l|}{2015} & \multicolumn{2}{|l|}{2016} & \multicolumn{2}{|l|}{2017} & \multicolumn{2}{|l|}{2018} & \multicolumn{2}{|l|}{2019} \\
\hline & women & men & women & men & women & men & women & men & women & men & women & men \\
\hline President & $0(0)$ & $1(100)$ & $0(0)$ & $1(100)$ & $0(0)$ & $1(100)$ & $1(100)$ & $0(0)$ & $1(100)$ & $0(0)$ & $0(100)$ & $1(0)$ \\
\hline SSA committees members & $6(55)$ & $5(45)$ & $8(73)$ & $3(27)$ & $8(62)$ & $5(38)$ & $8(62)$ & $5(38)$ & $8(53)$ & $7(47)$ & $6(46)$ & $7(54)$ \\
\hline SSA executive members & $1(33)$ & $2(66)$ & $1(33)$ & $2(66)$ & $1(33)$ & $2(66)$ & $2(66)$ & $1(33)$ & $2(66)$ & $1(33)$ & $2(66)$ & $1(33)$ \\
\hline SSA all committee members & $7(47)$ & $8(53)$ & $9(60)$ & $6(40)$ & $9(53)$ & $8(47)$ & $11(65)$ & $6(35)$ & $11(58)$ & $8(42)$ & $8(47)$ & $9(53)$ \\
\hline
\end{tabular}

Data are given as $n(\%)$. SSA, Stroke Society of Australasia.

motion, presentations at scientific conferences, society leadership, and journal editorial representation [3-6]. On the other hand, mentoring and sponsoring of women in medical research are acknowledged as important actions for creating equity and diversity $[4,6]$.

Although the underrepresentation of women in many areas in stroke research has been recognized through studies in North America and Europe $[5,7,8]$, few data pertain specifically to the Australasian-Pacific region. The Stroke Society of Australasia (SSA) is a professional organization of stroke clinicians (physicians, nurses, physiotherapists, occupational therapists, psychologists etc.), researchers (epidemiologists and basic scientists) and professionals from government and non-government organizations. Founded in 1989 with the aim of promoting research, training, services, and public policy to reduce the burden of stroke, SSA members are predominantly from within Australia. Its annual conference, often in cooperation with an Asia Pacific Stroke Conference and Australasian Nursing and Allied Health Stroke Conference, attracts a large international audience. Herein, we report the representation of women and men within the SSA leadership group and annual conferences between 2014 and 2019. We further explore the representation of women at conferences in relation to different speaking roles.

\section{Materials and Methods}

Data were obtained from the SSA on committee members and were grouped according to president, executive members (vicepresident, secretary, and treasurer), and committee members (ordinary and co-opted members). Speaker roles were grouped into keynote, invited, other speakers (which were included on abstract submissions), and all speakers. Names of SSA committee members were taken from the SSA Web site, while conference program committee members, speakers, and moderators were from the final programs of conferences from 2014 to 2019. Mem- bers of the executive committee and the president of the SSA are able to hold a maximum of 3 years per term. Data were only taken from SSA committee members and speakers of the SSA conferences. Gender was determined by name inspection and internet search. As data used in this study are available in the public domain, informed consent or Ethics Committee approval was not required according to Australian guidelines. Access to deidentified data is available upon reasonable request through the corresponding author.

Absolute numbers or percentages of women and men are reported in each category by year. Associations between the percentage of women in various speaking roles in conferences and the overall percentage of women on program committees were analysed using binomial regression. The percentage of women on the program committee was further dichotomized as more or less than one-third, this being the approximate median proportion of women on program committees over all the years studied and analysed similarly. We also tested the association between women's proportionate representation in speaker roles and the conference being, or not, combined with nursing and allied health, with and without adjustment for more than a third of women being on the program committee. All data analyses were performed in Stata, version 15 .

\section{Results}

Between 2014 and 2019, the presidency of the SSA was held by women for 2 years and by men for 4 . Committee members were predominantly women (55\% overall), with the highest percentage in $2017(65 \%)$ and lowest in 2014 and 2019 (47\%) (Table 1).

In 2015 and 2018, the conference was a combined SSA and Australasian Nursing and Allied Health stroke conference, while 2016 was a combined SSA and Asia Pacific Stroke Organisation conference. The gender distribution of speaker roles during the SSA conferences varied widely between year and type of speaker role (Fig. 1). For keynote speakers, the overall percentage of women was $41 \%$, with a higher percentage in 2015 (75\%); an equal percent- 


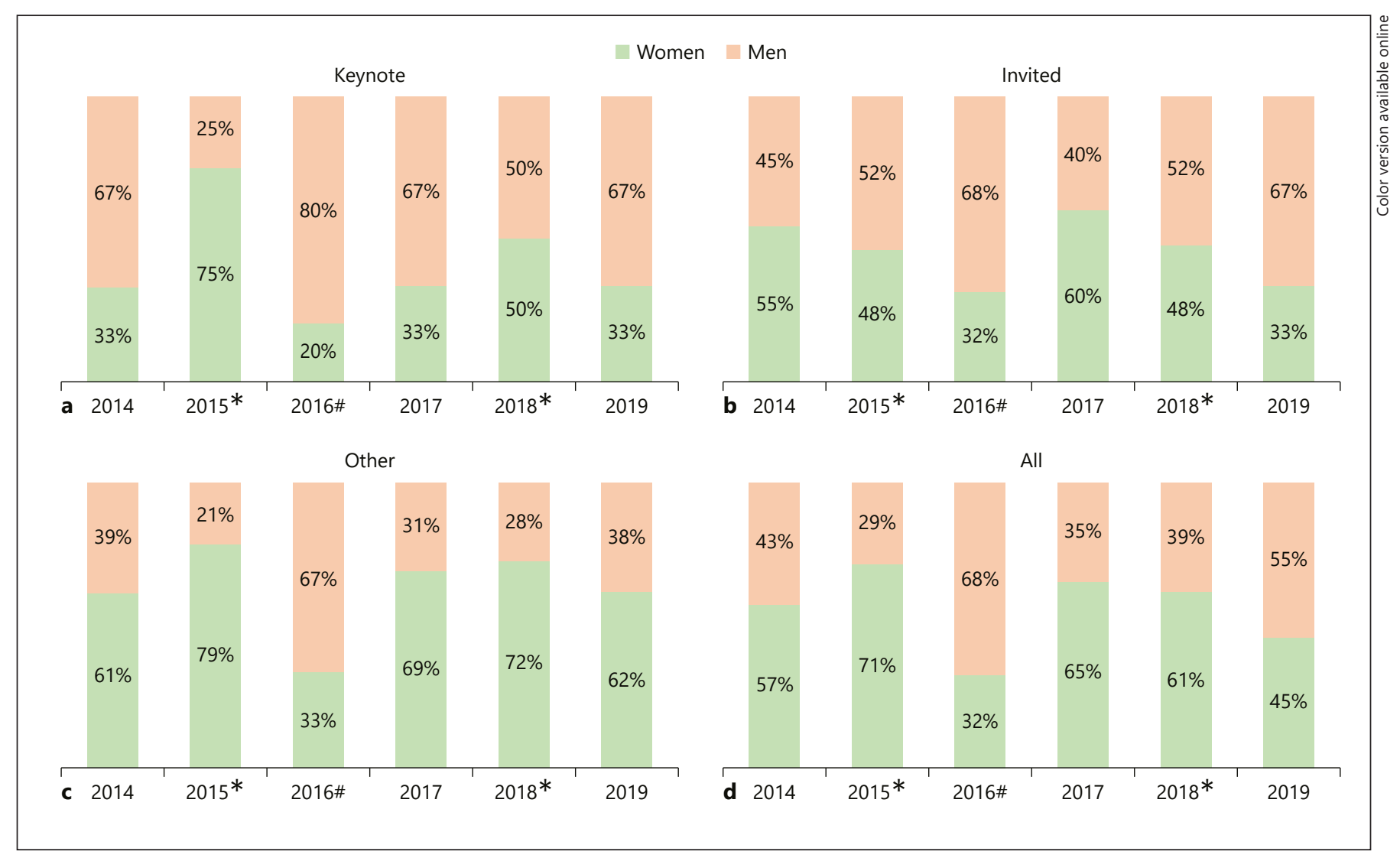

Fig. 1. Speaker roles at the SSA conferences from 2014 to 2019 by gender. a Keynote speakers. b Invited speakers. c Other speakers. d All speakers. *The conference was a combined SSA and Australasian Nursing and Allied Health stroke conference $(2015,2018)$. \#The conference was a combined SSA and Asia Pacific Stroke Organisation conference (2016). SSA, Stroke Society of Australasia.

age of women and men in $2018(50 \%)$ and a lower percentage of women in 2014 (33\%), 2016 (20\%) 2017 (33\%), and 2019 (33\%). Women being equally, or more, represented than men coincided with the combined SSA and Australasian Nursing and Allied Health Stroke conferences. From 2014 to 2019, 66\% of all speakers (keynote, invited, and other) were women, with the highest percentage in 2015 (71\%) and lowest in 2016 (32\%).

There were no data for moderators in the year 2015 and 2016 (Table 2). Forty-nine per cent of the moderators for the speaker sessions were women, highest proportion in 2018 (60\%) and lowest in 2014 (40\%). For the program committee, there were overall $44 \%$ women from 2014 to 2019.

There was a $2-4 \%$ increase in the proportion of women in speaking and moderating roles for every $10 \%$ greater representation of women on the program committee (Fig. 2). There was a statistically significant relationship between women's representation on program committees and the percentage of women in the roles of invited speaker, other speaker $(p \leq 0.001)$, and moderator $(p=$ 0.002 ). For keynote speakers, the positive relationship was not significant ( $p=0.13$ ), but when keynote and invited speakers (i.e., major speaking roles) were taken together, the relationship with gender make-up on the program committee was clearly significant $(p<0.001)$; a similar result was evident for all speaking roles taken together $(p<0.001)$. A program committee with over a third of its members composed of women was associated with a higher percentage of women as speakers or moderators, according to all grouped classifications (Table 3; $p<0.044)$. Similar findings were seen for the relationship of women in speaking roles for a combined SSA and nursing and allied health conference, but this was explained by the program committee comprising over a third of women. 
Table 2. SSA conference moderator and program committee membership from 2014 to 2019 by gender

\begin{tabular}{|c|c|c|c|c|c|c|c|c|c|c|c|c|}
\hline \multirow[t]{2}{*}{ SSA conference } & \multicolumn{2}{|l|}{2014} & \multicolumn{2}{|l|}{2015} & \multicolumn{2}{|l|}{2016} & \multicolumn{2}{|l|}{2017} & \multicolumn{2}{|l|}{2018} & \multicolumn{2}{|l|}{2019} \\
\hline & women & men & women & men & women & men & women & men & women & men & women & men \\
\hline Moderator & $16(40)$ & $24(60)$ & - & - & - & - & $19(49)$ & $20(51)$ & $49(60)$ & $32(40)$ & $29(45)$ & $35(55)$ \\
\hline Program committee & $2(29)$ & $5(71)$ & $6(67)$ & $3(33)$ & $3(30)$ & $7(70)$ & $5(42)$ & $7(58)$ & $5(71)$ & $2(29)$ & $1(25)$ & $3(75)$ \\
\hline
\end{tabular}

Data are given as $n(\%)$. SSA, Stroke Society of Australasia.

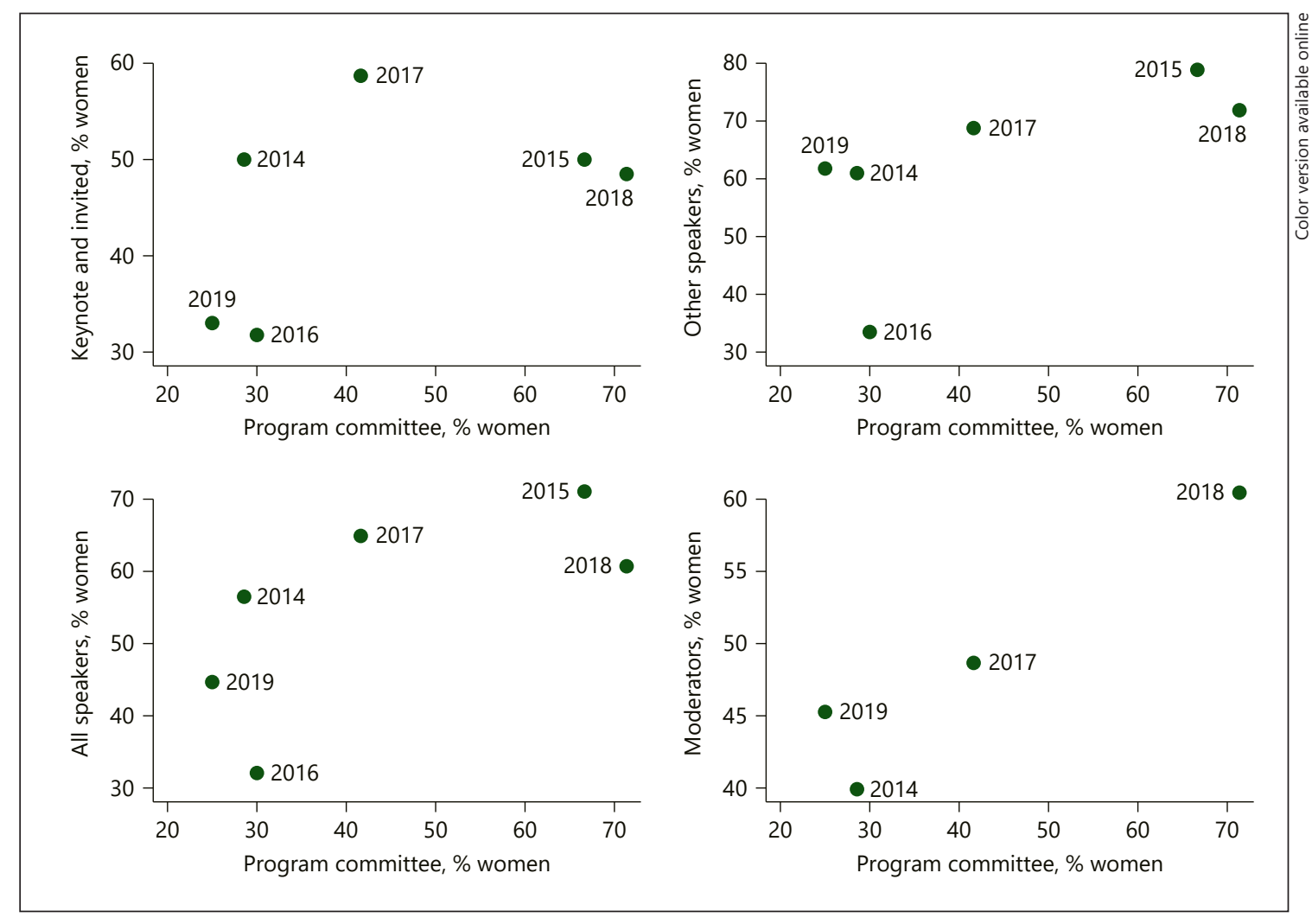

Fig. 2. Association between women's representation in a program committee and the proportion of women in speaking and moderating roles. The green dots represent years 2014-2019. Data on moderators were not available during the years 2015-2016.

\section{Discussion}

The representation of women in the SSA varies according to roles. In the leadership group, women were less likely to be elected president but were well represented as committee members. In annual conferences, there were generally less women invited as keynote speakers, but the reverse occurred in some years where the conference was combined with a conference for nursing and allied health professionals. Our findings also show that a higher proportion of women in a program committee was associated with a higher proportion of women in any speaking or moderating role, increasing by as much as one-fifth higher in the other and all speaker category.

Leadership positions in medical societies influence advancement in academia and medicine more broadly. Our findings show that over several years, there were only 2 years where a woman held the position of SSA president. This is somewhat better than in a North American study where there were no women president in the American Academy of Neurology in a 10 years period (2008-2017) [3]. However, it is important to note that the SSA is a more multidisci- 
Table 3. Association between representation of women in conferences and the percentage of women in speaking roles

\begin{tabular}{|c|c|c|c|c|c|c|c|}
\hline Speaker role & $\begin{array}{l}<\text { one-third } \\
\text { women, } \%\end{array}$ & $\begin{array}{l}\text { >one-third } \\
\text { women, } \%\end{array}$ & $p$ value & $\begin{array}{l}\text { not combined, } \\
\%\end{array}$ & $\begin{array}{l}\text { combined, } \\
\%\end{array}$ & $\begin{array}{l}p \text { value } \\
\text { unadjusted }\end{array}$ & $\begin{array}{l}p \text { value } \\
\text { adjusted* }\end{array}$ \\
\hline Keynote and invited speaker & 38.3 & 52.4 & 0.001 & 43.4 & 49.2 & 0.50 & 0.23 \\
\hline Other speaker & 52.1 & 73.3 & 0.001 & 56.2 & 75.5 & 0.001 & 0.27 \\
\hline
\end{tabular}

Data are given as percentages. * Adjusted for the percentage of women on the program committee being less or more than one-third.

plinary society than European and North American counterparts which likely influences the gender balance.

While the gender distribution of the speaking roles varied throughout, the overall percentage of women in the most highly regarded role (keynote) was well below $50 \%$, whereas $75 \%$ of the other speakers (abstract submissions) were women. This pyramid-shaped gender distribution may be considered as the glass-ceiling effect of the healthcare sector where there is an "unseen, yet unbreakable barrier that keeps minorities and women from rising to the upper rungs of the corporate ladder, regardless of their qualifications or achievements." [6] Our results where women are underrepresented as keynote speakers in the SSA support findings from other major scientific stroke conferences and confirms that this underrepresentation is not isolated in the Asia Pacific region. Data from the International Stroke Conference, held in the United States, showed that women represented only $28 \%$ of invited speakers from 2014 to 2018, with even larger disparities seen in women with ethnic minority backgrounds. For the European Stroke Organization Conference, this disparity has narrowed where women in the European Stroke Organization Conference faculty (composed of invited speakers and conference convenors) increased from $21 \%$ in 2015 to $40 \%$ in 2018. The European Stroke Organization's Top Down and Bottom Up approach, where attaining gender equality was made a priority in organizational and conference committees, and was a likely contributing factor to the increase in women [7].

Women role models, or women in leadership roles, are more likely to lead initiatives in gender equality $[6,9]$. In our study, women are more likely to attain good representation as speakers when they are relatively well represented in the program committee (whose role includes inviting speakers to the conference). This should encourage women to join such committees and provide a women's

Gender Equity at the Stroke Society of Australasia voice at conferences. We note that the SSA has now ensured that the gender of participants in conferences is recorded as part of conference evaluations, which may help with initiatives to monitor and increase gender balance.

More work is required to achieve gender equality in conferences and more generally in academia. Women need to be more visible in leadership roles, which gives them visibility, and an inspiration to younger generations to progress and achieve in academia. An approach suggested by Dr. Julie Silver [6] for \#SheLeadsHealthcare @ Twitter encourages to "(1) Invite Her, (2) Cite Her, (3) Quote Her, (4) Sponsor Her, (5) Recognize Her, (6) Pay Her, and (7) Promote Her." A further movement asks leaders of organizers to make an explicit pledge to promote diversity on panels and conferences $[10,11]$ more broadly. Finally, the major gatekeepers of advancement in academia (medical schools, funding agencies, medical journals, and professional medical societies) should set clear, specific goals and guidelines, and identify and address evidence, on gender bias in their areas. An example of a clear guideline would be to make formal hiring, promotions, and reviews fair, relying less on sponsor activities of leaders, who are often men. Previous studies have shown that men prefer to hire other men in male-dominated professions and can be illustrated by the so-called old boys network where male leaders "feel more socially similar to, or experience more interpersonal fit with, prospective male successors, which leads them to evaluate these successors more positively" [12].

We acknowledge several limitations to our study. We only assessed several recent years of the SSA in the 3 decades since its establishment. As a retrospective study that relied on limited printed information, we were unable to obtain broader information regarding the breakdown of equity according to topics (acute care vs. allied health and rehabilitation), the gender of professional groups represented among 
conference attendees or the gender of SSA members which may have influenced gender in other speaker categories. In addition, gender data from other international stroke conferences or societies were not available for direct comparison; however, publications in this area have already noted gender disparities in speaking [8] or leadership roles [7].

\section{Conclusion}

The purpose of this study was to examine whether women are underrepresented in leadership groups and at a major scientific conference. Women were less likely to be elected president and invited as a keynote speaker from 2014 to 2019 . An important finding is that increasing the number of women in program committees increases the number of women speakers at the SSA. While representation at the SSA may be better than that of its North American and European counterparts, increased efforts are needed to improve gender equality.

\section{Acknowledgement}

The authors would like to thank the SSA for their assistance and support in the conduct of this study.

\section{Statement of Ethics}

As data used in this study are available in the public domain; informed consent or Ethics Committee approval was not required according to Australian guidelines.

\section{Conflict of Interest Statement}

C.C., C.S.A., C.D., J.B., and S.G. are members of the Stroke Society of Australasia. S.G. is a committee member, and C.C. and C.D. are members of the Emerging Stroke Clinician and Scientist special interest group of the Stroke Society of Australasia.

\section{Funding Sources}

C.C. is funded by a National Heart Foundation of Australia Postdoctoral Fellowship (102741). S.G. is funded by a National Heart Foundation of Australia Future Leader Fellowship (102061) and reports funding from the NHMRC (APP143155, APP1182071) not related to this research. S.G. is currently an SSA committee member.

\section{Author Contributions}

C.C., J.B., and S.G. contributed to the concept of the study. C.C. wrote the first draft of the article. M.W. contributed to statistical analysis. All authors participated in interpreting results, drafting, and approval of the final article, and take responsibility for the content of this article.

\section{Data Availability Statement}

Access to de-identified data is available upon reasonable request through the corresponding author.

\section{References}

1 Gabster BP, van Daalen K, Dhatt R, Barry M. Challenges for the female academic during the COVID-19 pandemic. Lancet. 2020; 395(10242):1968-70

2 Pinho-Gomes A-C, Peters S, Thompson K, Hockham C, Ripullone K, Woodward M, et al. Where are the women? Gender inequalities in COVID-19 research authorship. BMJ Glob Health. 2020;5(7):e002922.

3 Silver JK, Ghalib R, Poorman JA, Al-Assi D, Parangi S, Bhargava $\mathrm{H}$, et al. Analysis of gender equity in leadership of physician-focused medical specialty societies, 2008-2017. JAMA Int Med. 2019;179(3):433-5.

4 Silver JK. Understanding and addressing gender equity for women in neurology. Neurology. 2019;93(12):538-49.
5 Fournier EL, Hopping GC, Zhu L, PerezPinzon MA, Ovbiagele B, McCullough LD, et al. Females are less likely invited speakers to the international stroke conference: time's up to address sex disparity. Stroke. 2020;51(2):674-8.

6 Cordonnier C, Coutts SB, Johnston KC, Rost NS. Crucial role of women's leadership in academic stroke medicine: you can't be what you can't see. Stroke. 2019;50(6):E149-52.

7 Sandset EC, Aguiar de Sousa D, Christensen $\mathrm{H}$, Cordonnier C, Fischer U, Katan M, et al. Women in the European stroke organisation: one, two, many...- a top down and bottom up approach. Eur Stroke J. 2019;4(3):247-53.

8 Guzik AK, Kapral MK, Bishop LE, Barghouthi TT, Vu QD, Husseini NE, et al. Abstract TMP75: gender disparities in international stroke conference leadership. Stroke. 2019; 50(Suppl 1).

9 McGregor AJ. Gender inequity in academic medicine: a visible sign of a disseminated disease. J Womens Health. 2002;29(2):137-8.

10 The Lancet Group. The Lancet Group no allmale panel policy. Aug 17. Available from: https://www.thelancet.com/diversity.

11 Male Champions to Change. Committ to the panel pledge. Available from: https://malechampionsofchange.com/commit-to-thepanel-pledge/.

12 Rink F, Stoker JI, Ryan MK, Steffens NK, Nederveen Pieterse A. Gender differences in how leaders determine succession potential: the role of interpersonal fit with followers. Front Psychol. 2019 May 3;10:752. 